\title{
"Morte Moderna" e "Morte Contemporânea": Formas Distintas e Contemporâneas de Expropriação
}

\author{
RAYMUNDO HERALDO MAUÉS
}

\begin{abstract}
MENEZES, Rachel Aisengart.
Em busca da boa morte: antropologia dos cuidados paliativos. Rio de Janeiro: Fiocruz e Garamond, 2004. 225 p.
\end{abstract}

Comprei o livro de Rachel Aisengart Menezes em outubro de 2005, durante o XXIX Encontro Anual da ANPOCS, quando participava, como assistente, do GT "Pessoa, Família e Ethos Religioso", depois de ouvir e comentar a comunicação que a autora fez na sessão do dia 28 de outubro (MENEZES, 2005). O que mais me impressionou e que anotei na ocasião foi a expressão "morte usurpada", com referência a uma forma de morte, no ambiente hospitalar, relacionada a um tipo de exacerbação do processo curativo em relação à morte no ambiente familiar. Essa expressão se referia, se me lembro bem, ao que a autora chama de "morte moderna", onde ocorre aquilo que é às vezes chamado de "encarniçamento terapêutico", em que o doente é isolado num Centro de Tratamento Intensivo (CTI) e permanece, longe de seus amigos e familiares, ligado a aparelhos da moderna tecnologia médica, mesmo que isso seja completamente inútil para a obtenção da cura de sua doença. Anteriormente, em sua dissertação de mestrado (MENEZES, 2000), a autora se dedicou a fazer a etnografia do CTI de um hospital público universitário do Rio de Janeiro. Ali constatou que, embora a prática médica seja vista como estruturada sobre a dupla dimensão do "cuidado" e da "competência", os profissionais desse setor atuam, não obstante, apoiados sim em seu saber, mas, ao mesmo tempo, em sua subjetividade e valores culturais. Por outro lado, o CTI possui como principal característica "o processo de negação da morte", pois nele se encontra como exemplar "uma prática médica voltada ao prolongamento artificial da vida" e "uma forma de gestão das emoções, na qual há pouco espaço para expressão de sentimentos - de pacientes, familiares ou profissionais" (MENEZES, 2006). 
Mas, ao mesmo tempo, não consegui me sentir confortável com o relato e a descrição das práticas do Hospital do Câncer IV, do Instituto Nacional do Câncer, também localizado no Rio de Janeiro, onde a autora realizou sua pesquisa para a tese de doutorado (MENEZES 2004), que segue o modelo dos cuidados paliativos destinado aos pacientes terminais ("fora de possibilidades terapêuticas"/FPT), cujo propósito é oferecer, a esses pacientes, bem como a seus familiares, uma assistência que se destina à "totalidade biopsicossocialespiritual". Fiquei também mais especificamente (mal) impressionado com o relato de uma sessão especial de orações, diante do leito de uma mulher idosa, promovida por seus familiares, com a presença de um número maior de visitas do que o permitido pela instituição, durante a qual, na visão da assistente social (católica) que permitiu a sessão, a paciente "que estava em coma, não ficou nada bem", chegando mesmo a se "agitar, balançar na cama e tremer, como se estivesse "baixando o santo"". Em conseqüência disso e interpretando subjetivamente - os possíveis sentimentos da paciente, a assistente social foi obrigada a intervir, pedindo que as orações fossem interrompidas e as pessoas se retirassem (MENEZES, 2004, p. 190; 2005, p. 19; 2006, p. 188). Na ocasião em que ouvi esse relato, durante a reunião da ANPOCS, pensei comigo mesmo e - depois - externei publicamente meu pensamento, de que não desejaria também que minha privacidade como doente - mesmo que já estivesse em coma - fosse usurpada, expropriada e invadida por tais tipos de rituais.

O livro de Rachel Aisengart Menezes é um trabalho excelente para se entender e refletir a respeito dessas questões que, como a própria autora indica, dizem respeito ao chamado "poder médico", mas, ao mesmo tempo, fazem referência a uma totalidade social, constituindo também, entre outras coisas, um excelente espaço de reflexão sobre a sociedade brasileira como um todo, com sua visão de mundo e o ethos a ela associado. O livro, de leitura agradável, é resultado de sua tese de doutorado, já referida, estando dividido em duas partes. A primeira, "Uma nova construção social da morte", contém um histórico, uma descrição e análise do ideário da "morte contemporânea", em oposição e em substituição ao conceito de "morte moderna", assim como também da nova disciplina ou especialidade médica a ela associada, a dos "Cuidados Paliativos". A segunda parte do livro, intitulada "Uma nova organização social do morrer", contém a etnografia resultante do trabalho da autora no Hospital do Câncer, dedicado aos cuidados paliativos no Rio de Janeiro. São descritos inicialmente o cenário e os atores (isto é, os membros da equipe interdisciplinar de médicos, enfermeiros, assistentes sociais e psicólogos), bem como sua formação teórica. 
Em seguida, a autora fala a respeito dos pacientes e seus familiares, em subitens de dois capítulos finais que tratam da "construção de uma nova identidade do doente", "uma pedagogia da família", "negociação e tomada de decisões", "uma leitura de vida", "'morrer bem', 'morrer mal", "organizando a cena da morte", "após a morte" e "gestão das emoções".

Como não seria possível, nem desejável, abordar aqui todas essas questões, vou limitar-me àquelas que me pareceram mais relevantes, especialmente para destacar as contribuições mais importantes, tanto no que diz respeito ao conhecimento factual quanto teórico do problema fundamental que o livro aborda: a construção do modelo da "boa morte" na sociedade brasileira, a partir da observação do que ocorre num local específico - um hospital de cuidados paliativos destinado a pacientes considerados FPT - e numa cidade específica, mas muito representativa: o Rio de Janeiro. Creio que a mesma pesquisa, com resultados semelhantes, poderia ser realizada em outras capitais brasileiras, mas o Rio de Janeiro, como antiga capital da República, apresenta características especiais, que permitem uma reflexão muito produtiva para o conjunto da sociedade brasileira (sem esquecer as outras especificidades locais ou regionais).

Em primeiro lugar, então, a própria questão da "boa morte": como seu ideário é construído no Brasil, constituindo o que a autora chama de "morte contemporânea", em oposição à "morte moderna", que expropria o paciente e seus familiares de sua própria morte, em função de uma exacerbação do poder médico e do encarniçamento terapêutico colocado em cena em unidades tais como os CTIs. Assim, de acordo com Menezes (2004, p. 20), para

os divulgadores dos Cuidados Paliativos, a proposta de oferecer uma assistência não mais curativa, e sim voltada a cuidar e aplacar o sofrimento, surgiu em contraposição à prática médica eminentemente tecnológica e institucionalizada, na qual o doente é excluído do processo de tomada de decisões relativas à sua vida e à própria morte. Com o advento e a implementação prática desta nova abordagem, o processo do morrer passou a ser debatido entre todos os envolvidos - profissionais, doentes e seus familiares -, gerando assim uma forma diferente de administração do período final da vida do enfermo. Surgem novos profissionais e uma especialidade orientada para o último período da vida do doente. Os Cuidados Paliativos, seus ideólogos e instituições buscam criar uma nova representação social do morrer, viabilizada pela construção de modalidades inovadoras de relação 
entre profissionais de saúde e doentes/familiares, inseridas em novas práticas institucionais. O funcionamento destas unidades hospitalares de Cuidados Paliativos é regido por uma extensa produção discursiva acerca do processo de tomada de decisões relativas à doença, ao sofrimento e à morte.

O movimento em favor da boa morte começou no exterior (Europa e EUA) e mais tarde chegou ao Brasil, no final dos anos 1980. Aqui, como a autora deixa claro, sofreu as adaptações necessárias à cultura brasileira, mas permaneceram algumas inadequações. Entretanto, em termos ideais, o movimento se inspira, tanto no exterior como no Brasil, em princípios comuns:

A meta preconizada no ideário da "morte contemporânea" é a conclusão de uma obra, de preferência bela, harmoniosa e produtiva, busca infindável de si, da totalidade, da identidade individual, devendo resultar em um final de vida digno e belo. O produto desta construção conduz à idéia de uma estetização da morte, na qual o doente se mantém tranqüilo, uma vez acolhido por uma equipe que o trata de modo individualizado. Em sua singularidade, pode permanecer com suas características físicas, com suas roupas, adereços, em um ambiente personalizado: em casa ou no quarto do hospice [como são denominados os estabelecimentos desse gênero], decorado segundo sua escolha. Freqüentemente, à imagem da "bela morte" associa-se a idéia da "morte pacífica", aliada à manutenção da identidade pessoal: a beleza está intimamente ligada às idéias de paz e harmonia. A "boa morte" é produzida por quem está morrendo e o produto deve ser belo (MENEZES, 2004, p. 47).

Outro elemento importante diz respeito à analogia que é feita entre a morte e o nascimento, através da metáfora da "viagem". Autores que preconizam os ideais da boa morte argumentam que, assim como "há uma preparação para o parto, com exercícios corporais e rituais [...], da mesma forma, em relação ao morrer, poderiam ser desenvolvidas técnicas e práticas, voltadas a uma redução da ansiedade diante da morte" e, além disso, que "o morrer poderia ser vivido à semelhança do parto - um processo de êxtase para muitas mulheres" (p. 48). Além disso, no treinamento que é oferecido aos novos profissionais são projetadas imagens sugestivas, como a de uma jangada no mar e, quando o tema é a morte, a imagem é alterada, "passando a um pôr do sol ou uma árvore no outono" (p. 96). Trata-se, em todos os casos, de imagens ou metáforas tradicionalmente associadas à morte. Não poderia deixar aqui de 
lembrar, também, que num contexto muito diferente, observado por mim durante meus trabalhos de campo sobre religião e medicina popular no litoral da Amazônia, pude observar várias vezes essa associação simbólica entre nascimento e morte. Assim, por exemplo, numa povoação de pescadores, na ilha de Itapuá (município de Vigia/PA), toda vez que nascia um bebê ou se fazia um velório, a vela de uma embarcação de pesca era desdobrada no recinto, numa clara alusão às duas "viagens".

Um segundo aspecto diz respeito às vinculações religiosas do movimento. Seus fundadores (a maioria mulheres), no exterior, eram pessoas religiosas; seu trabalho estava associado à salvação, não propriamente do doente, mas de si mesmos enquanto paliativistas. As duas influências mais marcantes, tanto no exterior quanto no Brasil, estão ligadas ao cristianismo (catolicismo) e à Nova Era. Daí também as imagens de viagem, de passagem, de paisagens naturais, etc. No Brasil se acrescenta, enfaticamente, um outro elemento, pertencente às formas de vivência religiosa populares, que incorporam fortemente as noções espíritas de um espírito autônomo em relação ao corpo. Essas noções se mesclam, muitas vezes, com concepções de natureza psicológica (da psicologia como ciência). O tema é desenvolvido mais amplamente por Rachel Aisengart Menezes em artigo recentemente publicado em Religião e Sociedade, que é produto de seu estágio de pós-doutoramento no Museu Nacional/UFRJ e no qual ela retoma muitos aspectos do que já tinha sido colocado na comunicação apresentada no GT da ANPOCS, antes referido. Nesse artigo, citando trabalhos de Luiz Fernando Dias Duarte, supervisor de sua pesquisa naquele Museu, Menezes (2006, p. 178) diz:

[...] compreende-se o religioso nas sociedades modernas não sob uma perspectiva nominalista linear, mas no sentido amplo de visão de mundo estruturante [...], de um sistema de referências e crenças. O espaço da religiosidade abarca, portanto, muitos valores e comportamentos oficialmente laicos ou não-confessionais [...]. Para que se compreenda mais claramente esse sentido, cabe distinguir em suas manifestações modernas três dimensões estruturantes: “1. 'religião' como identidade ou pertencimento; 2. 'religiosidade' como adesão, experiência ou crença; 3. 'ethos religioso' como disposição ética ou comportamental associada a um universo religioso" (DUARTE 2005, p. 141). O "ethos religioso" compreende uma relativa autonomia no que tange às comunidades religiosas, no contexto das sociedades contemporâneas. 
Em seguida, citando autores como Gilberto Velho, André Droogers e Yvonne Maggie, a autora enfatiza a importância da crença em espíritos dentro da sociedade brasileira e também o fato de que nela a feitiçaria não pode ser concebida como arcaísmo. Esse componente, que faz parte daquilo que Droogers chama de "religiosidade mínima brasileira", constitui um fato de grande relevância, ao ponto que católicos e até mesmo judeus podem utilizar e trabalhar com essas crenças. Por isso, entre os paliativistas observados no Hospital do Câncer, independentemente de suas confissões religiosas, tudo isso está presente e influencia as atitudes e prescrições desses profissionais no trato com os pacientes e seus familiares (cf. MENEZES, 2006, p. 185-187). Dessa forma, se se puder generalizar os resultados de uma pesquisa realizada num hospital do Rio de Janeiro, pode-se também dizer que as características culturais da sociedade brasileira acabam por influenciar e transformar uma proposta de tratamento de doentes terminais de câncer, considerados FPT.

E, para concluir, um último aspecto, já anunciado desde o título desta resenha. A autora, parcialmente fundamentada em Michel Foucault, assume também uma atitude crítica em relação à nova proposta de Cuidados Paliativos, que resulta do ideal da boa morte ou da morte contemporânea, em substituição à morte moderna. Apesar dos aspectos positivos dessa proposta, a mesma não deixa de reafirmar, em outros termos, o poder médico. Não sendo possível, aqui, resumir todos os argumentos utilizados pela autora, faço, no entanto, mais duas pequenas citações de seu texto:

O modelo de assistência paliativa surgiu em contraposição ao crescente poder do médico e de suas instituições. Contudo, o projeto de "humanização" do morrer é construído às custas da dependência - de doentes e familiares - de uma rede ampliada de profissionais. Não se trata, como afirmam os militantes da "boa morte", de uma libertação do aparato médico, mas sim de um refinamento e capilarização de suas formas de exercício de controle [...].

[A] equipe inserida em um hospital atua remetida a normas e regras institucionais. Desse modo, os profissionais, no enfrentamento de conflitos com doentes e familiares, podem tomar decisões baseadas em seus valores e referências culturais: permitem ou proíbem determinadas práticas, segundo seus próprios referenciais (MENEZES, 2004, p. 214 e 216).

Essas idéias remetem a algo que já foi dito por François Laplantine, em seu pequeno, mas excelente livro sobre antropologia da doença, no capítulo em 
que trata das relações entre doença e sagrado, medicina e religião, cura e salvação. Ali aparece claramente a possibilidade de o doente, por razões hedonistas ou culturais, rebelar-se contra as determinações médicas, até porque, como já o dizia outro antropólogo (Steven Polgar), lidando com o que os americanos chamam de antropologia da medicina, os médicos freqüentemente confundem prescrições fundamentadas na ciência com normas que pertencem a sua própria cultura (cf. LAPLANTINE, 1986; POLGAR, 1966). E todas essas, como no modelo do campo religioso formulado por Bourdieu (1974), são, de fato, formas de expropriação de bens simbólicos, que servem para reforçar o poder burocrático ou rotinizado do médico ou do sacerdote diante do paciente ou do leigo.

\section{Referências}

BOURDIEU, Pierre. A economia das trocas simbólicas. São Paulo: Perspectiva, 1974.

DUARTE, Luiz Fernando Dias. Ethos privado e justificação religiosa. Negociações da reprodução na sociedade brasileira. In: HEILBORN, M. L. et al. (Orgs.). Sexualidade, Família e Ethos Religioso. Rio de Janeiro: Garamond, 2005.

LAPLANTINE, François. A doença e o sagrado, a medicina e a religião, a cura e a salvação: da antropologia médica à antropologia religiosa. In:

Antropologia da doença. São Paulo: Martins Fontes, 1986. p. 213-251.

MENEZES, Rachel Aisengart. Difíceis decisões: uma abordagem antropológica da prática médica em CTI. Dissertação (Mestrado em Saúde Coletiva) - Instituto de Medicina social, Universidade do Estado do Rio de Janeiro, Rio de Janeiro, 2000 .

. Em busca da boa morte: antropologia dos cuidados paliativos. Rio de Janeiro: Fiocruz e Garamond, 2004.

. O momento da morte: Interpretação familiar e religiosidade. Trabalho apresentado no GT Pessoa, Família e Ethos Religioso, XXIX Encontro Anual da ANPOCS. Caxambu: Anais em CD, 2005.

. Observação etnográfica em hospital. Comunidade Virtual de Antropologia. Disponível em: http://www.antropologia.com.br/colu/colu23-b.htm. Acessado em: 17/07/2006. 
Religiosidade e interpretação da morte. Religião e Sociedade, v. 26. n. 1, p. 174-197, 2006.

POLGAR, Steven. A evolução e as doenças da humanidade. In:

Panorama da Antropologia. Lisboa: Fundo de Cultura, 1966. p. 221-232.

\section{NOTA}

- Doutor em Antropologia, Departamento de Antropologia da Universidade Federal do Pará. Endereço eletrônico: hmaues@uol.com.br. 